\title{
A Proposal for the Management of Plastic Packaging Waste
}

\author{
A. A. Akinola ${ }^{1}$, I. A. Adeyemi ${ }^{1}$ and F. M. Adeyinka ${ }^{2}$ \\ ${ }^{I}$ Department of Chemical Engineering, University of Lagos, Lagos, Nigeria \\ ${ }^{2}$ Nigerian Institute of Social and Economic Research (NISER), Ibadan, Nigeria
}

\begin{abstract}
An Environmental Impact Assessment study was performed using the Life Cycle Assessment (LCA) technique for a range of plastic packaging waste disposal technologies, to determine which waste management strategy has the potential to provide significant environmental benefits over existing waste management strategies. Comparisons were made between the various technologies; a number of scenarios are considered to build up supply chains for the disposal process. The Life Cycles of Plastic packaging waste disposed via the Landfill, Incineration and Integrated Plastic Waste Management (IPWM) methods were compared and their environmental burdens calculated using the Eco-indicator 99 method. The Single Score and Damage Assessment revealed that IPWM offers the most significant environmental benefits. Characterization plots of the effect on Climate change, Ozone layer depletion, Eco-toxicity, Respiratory organic and inorganic gases, Carcinogens , Radiation, Acidification/ Eutrophication, Land use and Minerals also confirmed that environmental benefits were most significant with IPWM.
\end{abstract}

Keywords : Life Cycle Assessment, Integrated Plastic Waste Management, Environmental Impact Assessment, Municipal Solid Waste

\section{Introduction}

The importance of managing waste to ensure the achievement of sustainable development cannot be overemphasized. In Rio, at the United Nations Conference on Environment and Sustainable Development, the provisions of Agenda 21 [1] reaffirmed that environmentally sound practices for the management of waste is a major issue that needs to be addressed for maintaining the quality of Earth's environment and achieving sustainable development. The environment is threatened because of unhealthy and unsustainable waste management practices. The challenge of ensuring environmental sustainability requires sustainable utilization of environmental resources, in addition to the effective management of solid and liquid wastes; these are also alluded to as targets that must be achieved in the Millennium Development Goal 7[2].

The growth of the consumer market worldwide continues to give way to a high use of plastic packaging, and its waste, which cause incalculable harm to the environment. Plastic waste are predominantly those used in packaging (plastic bags, plastic bottles and food boxes/packaging) and remain a large component of municipal solid waste (MSW ) whose disposal methods are yet to be adequately controlled, especially in the countries, such as Nigeria. According to the Federal Ministry of Commerce and Industry in Nigeria, production of the cheapest and most common source of drinking water, popularly known as "pure water" is one of the largest contributor to plastic packaging waste in the country. Plastic waste in the country is estimated to account for about $20 \%$ of total waste and, that $53 \%$ of all goods are packaged in plastics [3].

This paper contributes to the ongoing discourse on the environmental concerns and regulations to cut down on Greenhouse Gas (GHG) emissions, fossil fuel dependence, and the acknowledgement that it has become imperative to reduce the carbon footprint contribution from plastic packaging to the environment. The paper draws mainly from the findings of a study that had a main objective to assess the disposal scenarios of plastic waste, particularly packaging waste, and proposed suitable remedies for observed pitfalls. Life -Cycle Assessment (LCA) of existing waste management technologies were reviewed to serve as a tool for the identification of the waste management strategies that reflect Integrated Plastic Waste Management (IPWM). Specifically, this paper addresses the following research questions. What are the general environmental hazards associated with plastic wastes? What are the elements of the three waste management technologies in the context of the LCA executed? Which of the three options could be recommended for Nigeria? What are the challenges and constraints that come with the adoption of this option?

\section{Environmental Issues and Plastic Wastes}

The role that the improper disposal of plastics waste plays on the natural environment is increasingly being criticized on the one part due to volume of waste visible in the Nigerian environment; The inability of plastics to degrade at a reasonable rate also plays an important role. Edugreen [4], documents that it takes 
organic wastes such as vegetables; fruits peels and left-over foodstuff, as well as paper, a minimum of one week to a maximum of five months to degenerate. Cotton cloth degrades in about two to five years while woolen items degrades in about one year wood degrades in about 10 to 15 years, while Tin, Aluminum and other metal items such as cans degrade in about 100 -500 years. Edugreen [4], indicates that it takes about one million years for plastics to degrade. Furthermore, Greener Footprints, [5] have posited that plastics do not biodegrade, they photo-degrade. Indeed, plastics break down into smaller toxic components that eventually pollute the soil and waterways, clog up the drains causing water and sewage to overflow, and become the breeding grounds of germs and bacteria that spread diseases.

Plastics have replaced many of the traditional packaging materials such as wood, leather, paper, metal, glass and natural fibre products in a diverse range of applications. This is due to the ability to modify its properties of plastics to meet a vast array of designers' needs. Plastics can be processed to achieve a variety of properties including but not limited to strength, inertness, permeability/ imperviousness, durability, colour, touch/ texture, shape and resistance to various forms of degradation. The need to improve plastic packaging waste disposal practices and Municipal Waste Management practices in general has led environmental protection groups and environmental agencies to begin to clamor for bans on certain applications of plastic packaging.

There is now the emergence of biodegradable plastics after over 120 years of domination by traditional plastics made from non-renewable fossil fuels. Compostable Plastics are a new generation of plastics which are biodegradable and compostable. They are derived generally from renewable raw materials such as starch (e.g. corn, potato, tapioca etc), cellulose, soy protein, and lactic acid. The American Society for Testing \& Materials (ASTM) [6], defines compostable plastic as plastics "capable of undergoing biological decomposition in a compost site as part of an available program, such that the plastic is not visually distinguishable and breaks down to carbon dioxide, water, inorganic compounds, and biomass, at a rate consistent with known compostable materials (e.g. cellulose) and leaves no toxic residue." [7] The European Standards and The American Society for Testing \& Materials (ASTM)[6], indicates, that for a plastic to be considered compostable, the following three criteria need to be met, the plastic must be inherently biodegradable, the plastics possess the ability to disintegrate and the plastic must have no impact on the ability of the compost to support plant growth

There have been advances in the development of biodegradable plastics from renewable resources, especially for those products derived from starch-based materials. The objective is to develop biodegradable plastics that perform comparably with traditional petroleum-based plastics when in use and which completely biodegrade on disposal. Several Bio- or starch-based plastics have been introduced into the market, and are used in some applications now [8]. Bio- or starch-based plastics are made from corn, soy or potatoes. These plastics meet standards set by the American Society for Testing and Material (ASTM) [6], for composting, breaking down 60 percent or more within 180 days or less. An example of Bio- or starch-based plastics products is Spudware.[9] Spudware looks like traditional plastic flatware, except that it is compostable. Made from potato starch, Spudware is available in forks, spoons and knives.

Other earth-friendly bio- or starch-based plastic products included plastic cups made from corn, and plates and bowls made from sugar cane. Plastic recycling involves recovering waste or scrap plastic and reprocessing the material into useful products. The new product obtained may be completely different in form from their original state. For example, this could mean melting your used hair product bottles, both consumer or salon bottles, and then casting them as plastic chairs and tables.

\section{Life Cycle Assessment}

According to the International Standards Organization documents - ISO 14040[10] and ISO 14044, [11], a Life Cycle Assessment framework has four distinct phases as illustrated in the Fig. 1, the phases are often interdependent in that the results of one phase will inform how other phases are completed. The 'Goal Definition and Scoping' phase involves defining and describing the product, process or activity. Establish the context in which the assessment is to be made and identify the boundaries and environmental effects to be reviewed for the assessment. The 'Inventory Analysis' phase involves identifying and quantifying materials usage and environmental releases. The 'Impact Assessment' phase involves assessing the potential human and ecological effects of material usage and the environmental releases identified in the 'Inventory Analysis' Phase. The 'Interpretation' phase involves evaluating the results of the inventory analysis and impact assessment to select the preferred product, process or service with a clear understanding of the uncertainty and the assumptions used to generate the results. Details of the life cycle assessment framework, method, process and procedure are discussed extensively in literature[10,11,12, 13,14].

Life Cycle Assessment on different types of waste has been performed since the early 1990s [15] and there are today many Life Cycle Assessment tools available. A comprehensive list is provided by the European Commission, Joint Research Centre. Institute for Environment and Sustainability[16]. These tools have all been developed based on models with different scopes with regards to applicability, functionality, user friendliness 
and costs [17]. However, they all use the LCA framework shown in Fig 1. In the work done here, the SimaPro ${ }^{\circledR}$ 7.1 tool [18] will be used for Plastic waste material. The calculations in the SimaPro* 7.1 tool are based on the Eco-indicator 99 method[19,20].

\section{Method and Materials}

The waste management technologies considered here are Landfill, Incineration and IPWM ; these various waste management technologies consider the Raw material extraction for plastic production, the Manufacturing process the Distribution requirements, the Use and the End-life management systems. The Life Cycle Assessment (LCA) model shown in Fig. 1 is used for the work done here.

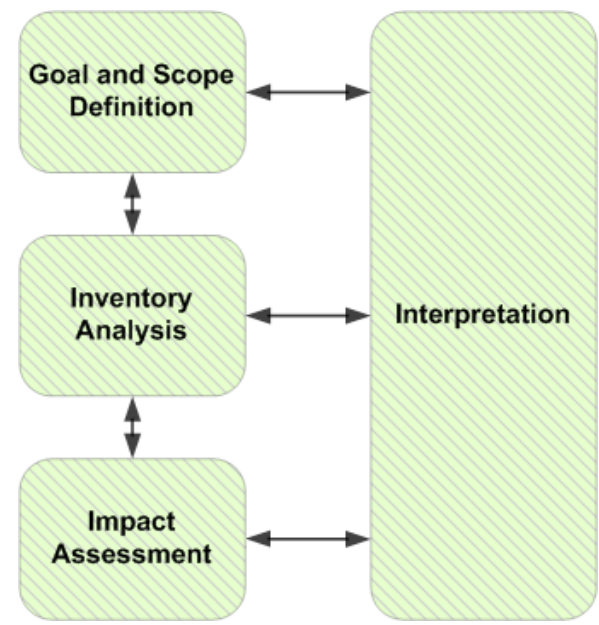

Fig. 1 : Life Cycle Assessment Model

\subsection{LCA Goal Definition and Scope Phase}

Three scenarios were considered for a waste management of Plastics and each was evaluated with respect to their environmental burdens and benefits. The scenarios are

Scenario A: $\quad$ Landfill (100\%)

Scenario B: $\quad$ Incineration $(100 \%)$

Scenario C: $\quad$ Integrated Plastic Waste Management (IPWM)

- Landfill (10\%), Incineration (20\%) and Recycling (70\%)

Scenarios A and B represent waste management practices of developing countries while Scenario $\mathrm{C}$ is the proposed Integrated Plastic Waste Management System (IPWM) system proposed to better handle waste in these developing economies.

The Life Cycle of $1000 \mathrm{~kg}$ of Plastic packaging waste disposed via three (3) waste scenarios and their environmental burdens were calculated using the Eco-indicator 99 method[19] Fig. 2 shows the constituent parts of the plastic packaging.

\subsection{Life Cycle Inventory (LCI) Phase}

Quantitative proportions of the constituent components of the plastic packaging are shown in Table 1.

Table 1: Quantitative Proportions of Constituent Components of the Plastic Packaging

\begin{tabular}{lll|l|l}
\multicolumn{2}{l|}{ Assemblies } & $\underline{\%}$ & Processes \\
\hline $\mathrm{PE} \rightarrow$ & $210 \mathrm{~kg}$ & (LDPE B250) & $21 \%$ & Extrusion, plastic film/RER S \\
$\mathrm{PE} \rightarrow$ & $190 \mathrm{~kg}$ (HDPE B250) & $19 \%$ & Blow moulding/RER S \\
$\mathrm{PVC} \rightarrow$ & $140 \mathrm{~kg}$ (PVC B250) & $14 \%$ & Extrusion, plastic pipes/RER S \\
$\mathrm{PP} \rightarrow$ & $230 \mathrm{~kg}$ & (PP granulate average B250) & $23 \%$ & Injection moulding/RER S \\
$\mathrm{PS} \rightarrow$ & $90 \mathrm{~kg}$ & (PS (EPS) B250 (1998)) & $9 \%$ & Foaming, expanding/RER S \\
$\mathrm{PET} \rightarrow$ & $140 \mathrm{~kg}$ & (PET bottle grade B250) & $14 \%$ & Blow moulding/RER S \\
\hline
\end{tabular}




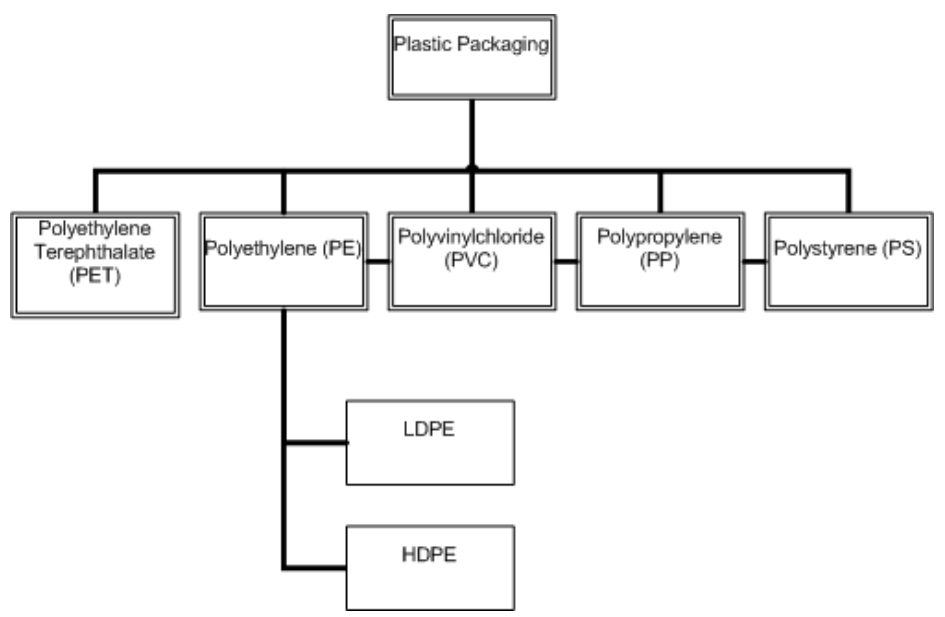

Fig. 2 Constituent components of the Plastic waste

\subsection{LCA Impact Assessment Phase}

The calculations in the default Eco-indicator 99 method [19], is used. In the Eco-indicator 99 method, normalisation and weighting are performed at three damage category level. The three damage categories are:

HH Human Health unit: DALY= Disability Adjusted Life Years; this means different disability caused by diseases are weighted

EQ Ecosystem Quality unit: $\mathrm{PDF} * \mathrm{~m}^{2} \mathrm{yr} ; \mathrm{PDF}=$ Potentially Disappeared Fraction of plant species

R Resources unit: MJ surplus energy Additional energy requirement to compensate lower future ore grade

Eco-indicator 99 has a damage assessment step; the impact category indicator results calculated in the Characterisation step are added to form damage categories. Addition without weighting is justified here because all impact categories that refer to the same damage type (like human health) have the same unit. This procedure can also be interpreted as grouping.

Table 2: Groupings for Damage Types

\begin{tabular}{l|l|l} 
Human Health & Ecosystem Quality & Resource Depletion \\
\hline Carcinogens & Ecotoxicity & Minerals \\
Resp. Organics & Acidification/ Eutrofication & Fossil Fuels \\
Resp.Inorganics & Land Use & \\
Climate Change & & \\
Radiation & & \\
Ozone Layer & & \\
\hline
\end{tabular}

\subsection{LCA Interpretation Phase}

Life Cycle Assessment (LCA) Interpretations are considered for the Single Score assessment, Damage assessment and Characterization per category

Single Score and Damage Assessment: Single score analysis of environmental burdens (Fig 3) revealed that Landfill results in the least environmental benefits as indicated by waste hierarchy, however the deficiencies of the waste hierarchy are put in the spotlight as Integrated Plastic Waste Management (IPWM) offers the most significant environmental benefits. In fact, in all three damage categories (Human Health, Ecosystem Quality and Resource depletion), IPWM results in the least environmental burden (Fig. 4).

Characterization per category: The characterization plot (Fig. 5) shows a more detailed analysis of the damage categories. The various impact categories considered were: Climate change (Emissions to air like hydrocarbons, carbon dioxide, methane etc.), Ozone layer (ozone depletion potential), Eco-toxicity (Emission to water, air and soil), Respiratory organic gases (Emissions to air, all kind of organics), Respiratory inorganic gases (Emissions to air, $\mathrm{SO}_{2}, \mathrm{NO}_{\mathrm{x}}$ ), Carcinogens (Arsenic, Benzene, Cadmium, Heavy metals etc.), Radiation (Emissions to air and water from Cobalt, Hydrogen, Radon, Plutonium etc.), Acidification/ Eutrophication (Emissions to air, Nitrogen, Ammonia etc.), Land use (Emission from raw material, traffic etc.), Minerals (Aluminum, Iron, Lead, Copper etc.).

\section{Results and Discussion}

The Life Cycles of $1000 \mathrm{~kg}$ of Plastic packaging waste disposed via the Landfill, Incineration and IPWM were compared and their environmental burdens calculated using the Eco-indicator 99 method. As indicated in the LCA Interpretation phase discussed earlier, the Integrated Plastic Waste Management (IPWM) 
method is favored over the Landfill or Incineration methods. The Single Score analysis ( Fig. 3) indicates that the damage to Human Health is smallest with the IPWM method with an environmental burdens score of 60 points. The land fill method had the largest score with 100 points and the incineration method had a score of 80 points. While the environmental burdens due to Ecosystems quality is within 5 points in all the 3 scenarios, the depletion to the environmental resources is smallest with the IPWM method which has an environmental burdens of 180 points and largest with the land fill method with an environmental burdens of 380 points (Fig $3)$.

Using the Eco-indicator 99 method, Damage Assessment analysis (Fig. 4) reveals that for the human health situations, the environmental burdens for IPWM is $40 \%$ lower than that of the land fill and $25 \%$ lower than that of the Incineration methods.. For Ecosystem Quality, the environmental burdens for IPWM is 25\% and $6 \%$ lower than that of the land fill and Incineration methods respectively and for the depletion of resources, the environmental burdens for IPWM is 50\% lower than for both the land fill and Incineration methods.

The Characterization per Category analysis (Fig 5) reveal, that the IPWM method is more beneficial than the Landfill or Incineration methods. The data and graphs indicate that the environmental burden for IPWM is lower than that of the land fill and the incineration methods

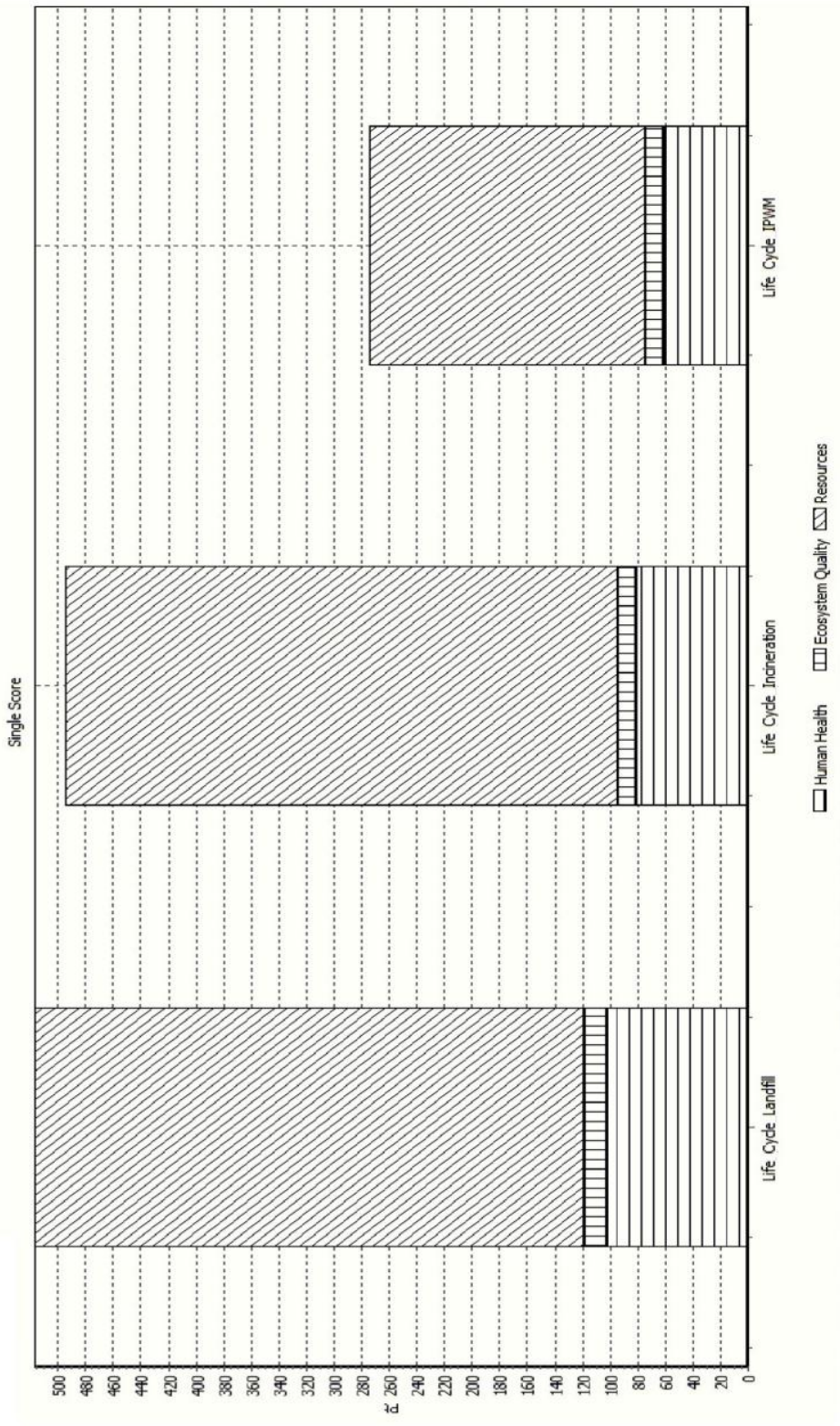

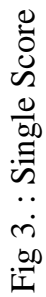




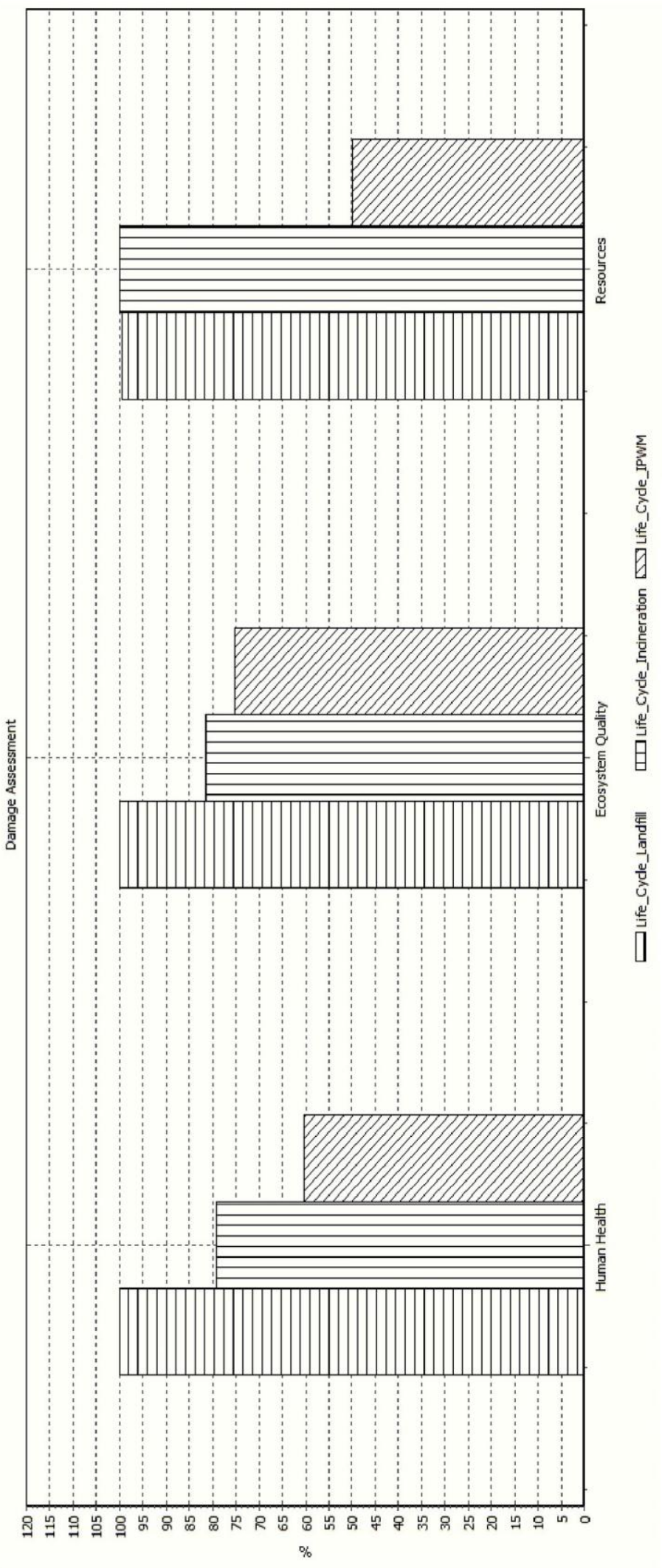

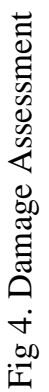




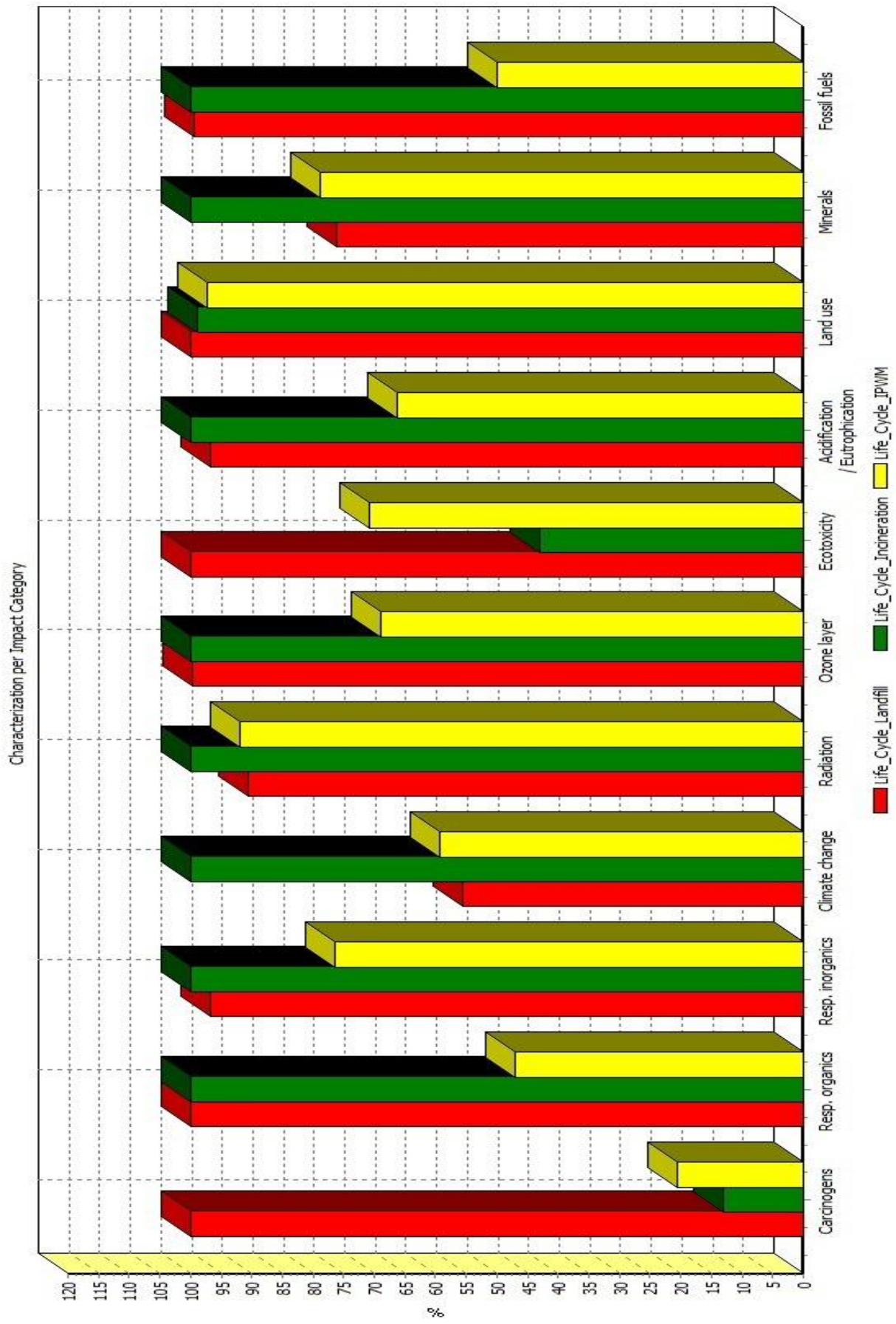

However, challenges come with the adoption of the Integrated Plastic Waste Management (IPWM)which include poor implementation in developing countries, lack of resources and institutional capability. Many communities do not have organized waste collection systems, waste loading or sorting and transfer facilities. Others may not possess waste treatment sites, or even enabling legislation or the financial resources. These are important stages in the life cycle of the plastic packaging materials and thus pertinent to the life cycle analysis. Integrated Plastic Waste Management (IPWM) would be the recommended method for developing countries due to its significantly higher environmental benefits. The higher the efficiency of the implementation plan the higher the environmental benefits to be gained.

It is worthy of note that a poorly implemented IPWM system often results in environmental impacts not far from that of Landfill method or the Incineration method. The shift to increased environmental benefits is proportional to the increased efficiency of the IPWM system. 


\section{Conclusions}

This study clearly indicates that the Integrated Plastic Waste Management (IPWM) best suits the waste management system for developing countries. The results of this study are especially important for countries whose low financial circumstances and low technological level dictate their waste management practices. The environmental presence of plastic waste as litter is an attitudinal problem in the "Use phase" and would be best solved by an aggressive campaign or sensitization as to the effects of such practices. The effects of plastic materials during the life cycle is not confined to just the disposal phase and the use phase; the production stage as well as the plastic product design stages also have roles to play. At the present time bio-degradable plastics are being researched, tested and produced

\section{REFERENCES}

[1] United Nations, Press summary of Agenda 21, Section II - Chapter 2: Sustainable management of solid wastes and sewage-related issues The United Nations Conference on Environment and Sustainable Development Rio, Brazil 1992: United Nations.

[2] United Nation, (2013), Millennium Development Goals and Beyond 2015, Retrieved October 1, 2013 from http://www.un.org/millenniumgoals/pdf/Goal_7_fs.pdf

[3] Waste Watch (2004), Packaging recycling information sheet, London. Retrieved 1-October-2013 from http://www.wasteonline.org.uk/resources/InformationSheets/Packaging.htm

[4] Edugreen (2010), Types of solid waste Retrieved July 8, 2010 from: http://edugreen.teri.res.in/explore/solwaste/types.htm

[5] Greener Footprints @ (2005-2010), Plastic bag facts, Retrieved 1-Oct-2013 from http://www.greenerfootprints.com/plasticbagfacts/

[6] ASTM D6400 - 12, May 2012, "Standard Specification for Labeling of Plastics Designed to be Aerobically Composted in Municipal or Industrial Facilities," ASTM International

[7] S. A. Mojo S. A., (2001), "What's Next for Biodegradable and Compostable Plastics? ", Retrieved 1-October-1, 2013 from http://www.astm.org/SNEWS/APRIL_2001/mojo_apr01.html

[8] K. Sriroth, \& K. Sangseethong, (2005, June). Biodegradable plastics from cassava starch. In II International Symposium on Sweet potato and Cassava: Innovative Technologies for Commercialization 703 (pp. 145-152)

[9] BioMass Packaging, (2011), "SpudWare , Cutlery that incorporates bioplastic to reduce the use of petroleum plastic", Retrieved October 1, 2013 from http://www.biomasspackaging.com/brands/255570-spudware

[10] ISO 14040 (2006): Environmental management - Life cycle assessment-Principles and framework, International Organization for Standardization (ISO), Genève, Switzerland.

[11] ISO 14044 (2006): Environmental management - Life cycle assessment - Requirements and guidelines, International Organization for Standardization (ISO), Genève, Switzerland

[12] J. B Guinée, J. B. (Ed), (2002), Handbook on Life Cycle Assessment: Operational Guide to the ISO Standards (Eco-Efficiency in Industry and Science), Springer; 2002 edition (May 31, 2002) ISBN-10: 1402005571 ISBN-13: 978-1402005572

[13] R. Horne, T. Grant, K. Verghese (2009), Life Cycle Assessment: Principles, Practice and Prospects, CSIRO Publishing (June 2009), ISBN-10: 0643094520, ISBN-13: 978-0643094529

[14] Scientific Applications International Corporation (SAIC), (May 2006), Cycle Assessment: Principles and Practice Scientific Applications International Corporation (SAIC), 11251 Roger Bacon Drive, Reston, VA 20190.

[15] A. J. Morrisey and J. Brown, Waste management models and their applications to sustainable waste management. Waste Management, 24, (2004)., pp 297-308

[16] European Platform on Life Cycle Assessment, EPLCA (2010) List of tools, European Commission: Direction General, Joint Research Centre. Institute for Environment and Sustainability. Retrieved April 2010 from: http://lca.jrc.ec.europa.eu/lcainfohub/toolList.vm.

[17] A. Damgaard. Implementation of life cycle assessment models in solid waste management, PhD Thesis, 2010, Department of Environmental Engineering, Technical University of Denmark.

[18] PRé Consultants, (2010a), SimaPro LCA Software, Retrieved October-01-2013 from: http://www.pre-sustainability.com/simaprolca-software

[19] M. Goedkoop and R. Spriensma, (June 2001), The Eco-indicator 99 A damage Oriented Method of Life Cycle Impact Assessment Methodology Report. Third Edition, PRe Consultants B. V., Plotterweg 12, 3821 BB Amersfoort, The Netherlands.

[20] PRé Consultants, (2010b), ReCiPe \& Eco-Indicator 99, Retrieved October-01-2013 http://www.pre-sustainability.com/impact assessment-methods 